\title{
Self-induction of epileptic seizures by eyeclosure: incidence and recognition
}

\author{
C D BINNIE, C E DARBY, R A DE KORTE AND A J WILKINS
}

From the Instituut voor Epilepsiebestrijding, Heemstede, The Netherlands, Runwell Hospital, Wickford, and the Medical Research Council Department of Applied Psychology, Cambridge

SUMMARY Self-induction of epileptic seizures is generally regarded as a rarity, chiefly observed in patients of subnormal intelligence. During EEG recordings with open eyes in a consecutive series of 48 photosensitive patients, however, 13 subjects induced paroxysmal activity or seizures by eyeclosure with forced upward deviation of the eyes. Eyeclosure on command produced a different type of oculographic artefact and induced paroxysmal activity in only one subject. Two patients were of subnormal intelligence but all displayed psychiatric or psychosocial problems. The incidence of induced paroxysmal activity was reduced by reduction of ambient lighting. Eight patients admitted self-induction of seizures. We conclude that this phenomenon occurs more often than was previously supposed and can be recognized by the recording in photosensitive patients of prolonged EEGs with eyes open and in a brightly lit environment.

Self-induction of epileptic seizures has been recognized for forty years ${ }^{15}$ and some 120 cases are described in the literature. The majority of patients are photosensitive and induce their attacks by means of visual stimuli. In most reported cases the patient gazes at the sun or a bright light and waves one hand in front of the eyes ${ }^{1}$; however, a few have been observed to use blinking movements. ${ }^{1491618}$ Self-induction of seizures is regarded as a rarity: Wadlington and Riley ${ }^{21}$ report two cases in 20000 EEGs; Gastaut ${ }^{6}$ estimates the incidence as one per 1000 patients with epilepsy. In the detailed study by Jeavons and Harding ${ }^{11}$ of 460 photo-sensitive patients, only five displayed self-induction attacks.

In the course of a study of pattern-sensitivity we had occasion to make prolonged EEG recordings from photosensitive patients with open eyes and found five subjects who induced paroxysmal activity or indeed seizures by eyeclosure. ${ }^{3}$ The present communication confirms the high incidence of self-induction in a larger, consecutive series of photosensitive patients.

Address for reprint requests: $\mathrm{Dr}$ CD Binnie, EEG Afdeling. Institute voor Epilepsiebestrijding, Achterweg 5, $2103 \mathrm{SW}$ Heemstede, The Netherlands.

Accepted 13 December 1979

\section{Material and methods}

Intermittent photostimulation (IPS) is routinely performed during EEG investigation in this department. The procedure is described in detail elsewhere ${ }^{22}$ but may be summarized as follows: a Grass photostimulator type PS22 is used at a distance from the nasion of approximately 300 $\mathrm{mm}$; the light is diffused and has an intensity of approximately $100 \mathrm{Nit}$-s per flash. Each stimulus train is delivered at constant frequency and not longer than $10 \mathrm{~s}$ and each frequency is tested in combination with the act of eyeclosure, then with eyes closed and finally with eyes open. For purposes of the study of pattern sensitivity the only subjects considered were those exhibiting a classical photoconvulsive response, ${ }^{2}$ which continued after termination of the stimulus (a socalled "prolonged photocompulsive response"). ${ }^{17}$

During the six months ending March 1979, 48 out of 979 patients met this criterion. Before the study of pattern sensitivity (which will not be considered further here) a base line recording of at least $10 \mathrm{~min}$ was performed with eyes open and the patient sitting upright in a well lit room. During this period 13 patients appeared to elicit paroxysmal activity by eyeclosure. These 13 patients were investigated further by means of a 
telemetric EEG recording of two to six hours with simultaneous video-registration. During this recording the patients were free to move about within a sitting room of some $40 \mathrm{~m}^{2}$ with an illumination intensity of approximately 3000 lux. For periods of 10 to 30 minutes the lights were extinguished and illumination reduced to 100 lux or less.

\section{Results}

A striking feature of all 13 subjects was that they made repeated slow eyeclosure movements with simultaneous upward deviation of the eyes, considerably more marked than that ordinarily seen as the eyes are shut. Under conditions of normal room lighting this was usually followed by spike and wave or multiple spike and wave activity either generalized or confined to the posterior regions of the head. In 11 patients one or more of these discharges was accompanied by a seizure, usually an absence.

The figure shows the typical oculographic artefact associated with the slow eyeclosure followed by generalized epileptiform activity. With a time constant of $0.3 \mathrm{~s}$, the oculographic signal was biphasic as illustrated, but with a time constant of $5 \mathrm{~s}$ it was seen to have a square waveform. Voluntary eyeclosure to command generally produced a different movement and no paroxysmal activity was seen. In only one subject were discharges elicited by eyeclosure to command and

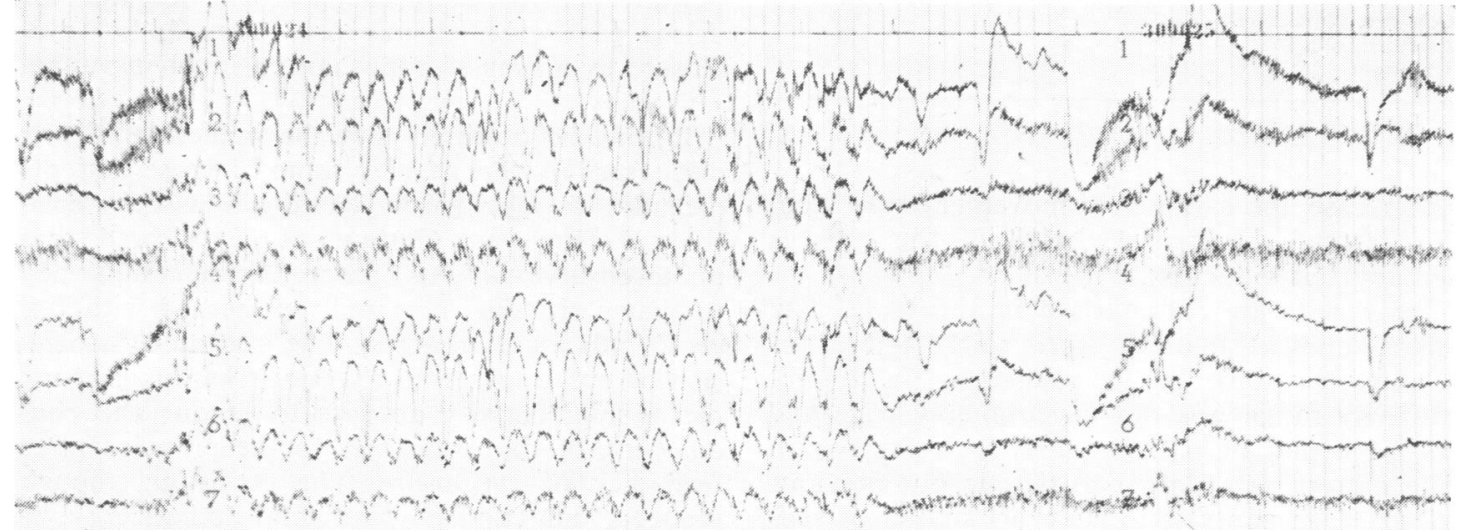

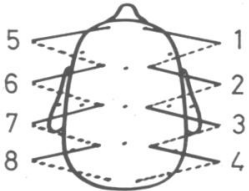

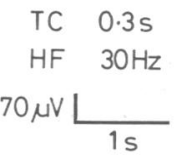

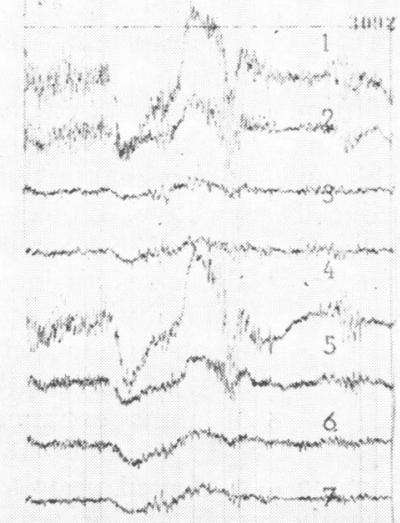

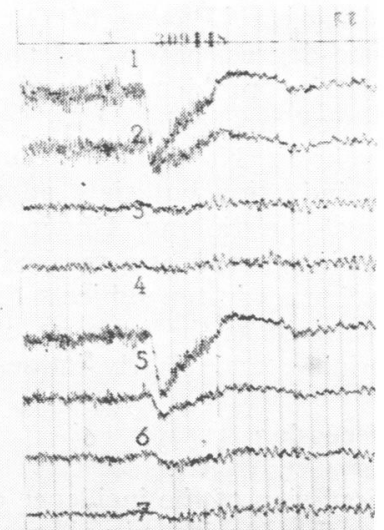

Figure EEG of an 18 year old man with primary generalised epilepsy. Above: Two slow eye-movements; the first is followed by a run of spike-wave activity, after the second much less paroxysmal activity occurs. Such variability is commonly found. Below left: A similar eye-movement performed in darkness without clear paroxysmal activity. Below right: Voluntary eyeclosure produces a different oculographic artefact and elicits no paroxysmal activity. 
Table Photosensitive patients (6 months to March 1979), total 48. With self-induced seizures or paroxysmal activity 13

$\begin{array}{ll}\text { Female 7, Male 6 } & \\ \text { Age (mean) } & 20 \cdot 4 \pm 7 \text { years } \\ \text { Of subnormal intelligence } & 2 \\ \text { Type of epilepsy: } & 5 \\ \text { Primary generalised } & 3 \\ \text { Partial } & 5 \\ \text { Secondary generalised } & \\ \text { Type of induced seizures: } & 7 \\ \text { Absence } & 2 \\ \text { Absence and tonic-clonic } & 2 \\ \text { Partial } & 2 \\ \text { No clinical change observed } & 5 \\ \text { Spontaneous seizures } & 7 \\ \text { Spontaneous paroxysmal activity } & \\ & 31 \pm 12 \mathrm{~Hz}^{-} \\ \text {Photosensitivity range } & \left.6 \text { (out of } 9^{*}\right) \\ \text { Television sensitive } & 8 \text { (out of } 11^{*} \text { ) } \\ \text { Pattern sensitive } & 8 \\ \text { Self-induction admitted } & \\ \text { Effect of reduced lighting on self-induction } & 6 \\ \text { Complete suppression } & 4 \\ \text { Partial suppression } & 3\end{array}$

* Not all subjects tested

in this case the same slow movement was seen, with extreme upward deviation of the eyes as used for self-induction.

The results are summarised in the table. The general clinical findings were fairly typical of IPS-sensitive subjects. In particular the photosensitivity range was not exceptionally wide and the proportion of patients sensitive to television or to pattern was similar to that in our previous series. ${ }^{1922}$ In contrast to previous studies of selfinducing patients only two were of subnormal intelligence. Eleven of our patients suffered to some degree, however, from psychosocial or psychiatric problems ranging from impending divorce proceedings to a frank schizophreniform psychosis. No patient volunteered a history of self-induction but eight admitted to the habit on direct questioning. Under conditions of reduced lighting there was a marked reduction of induced discharges in ten subjects. In three the effect was uncertain as the instance of discharges was low, variable, and clearly influenced by stress.

\section{Discussion}

Discussion of the incidence of clinical phenomena associated with visual sensitivity is frequently confused by the lack of any universally accepted definition of photosensitivity. It must be stressed that the criteria of sensitivity to IPS employed in the present study were considerably more rigorous than those of many authors, particularly in the contemporary German literature. ${ }^{5}$
Nevertheless it has been estimated that IPS sensitivity as defined for purposes of the present study occurs in some $5 \%$ of people with epilepsy ${ }^{11}$ and indeed the present findings closely agree with this figure. We find an incidence of self-induction in $27 \%$ of IPS sensitive patients or $1.3 \%$ of our original consecutive series of nearly 1000 epileptic subjects.

Epileptiform activity without the characteristic eyeclosure occurred in all 13 patients on IPS and also spontaneously in seven. Conversely, paroxysmal activity was not observed in association with every slow eyeclosure and the association became weaker or broke down entirely under conditions of reduced lighting. It therefore appears most improbable that the movement is to be regarded as itself a component of a seizure pattern and the findings support the view that the discharges were themselves induced by eyeclosure by means of a mechanism involving visual sensitivity.

It may be objected that the induction of any discharges in darkness by some of these patients excludes a mechanism based on visual sensitivity. ${ }^{12}$ However, Gastaut et $a l^{8}$ showed that photosensitive patients can readily be conditioned so that a stimulus repeatedly presented with IPS itself induces discharges. The repeated association of eyeclosure with a visual stimulus eliciting paroxysmal activity appears to favour the conditioning of the discharges to the proprioceptive feed-back of eyeclosure. The persisting, though reduced, induction of parxysmal activity by eyeclosure in darkness may therefore be based upon a conditioned reflex.

The original provocative stimulus remains uncertain. However, it is known that directly following eyeclosure the amplitude and frequency of alpha activity are increased ${ }^{20}$ spontaneous paroxysmal activity frequently occurs in photosensitive subjects ${ }^{10}$ and photosensitivity is increased. ${ }^{13}$ Forced upward deviation of the eyes also gives an increase in alpha activity ${ }^{14}$ and the similarity of this to the characteristic eye movements of our patients suggests that the discharges may be induced by a mechanism related to that of alpha enhancement.

In none of these patients was self-induction suspected prior to the EEG investigations. However, the present study has created a heightened awareness of the condition amongst our colleagues. Of a further ten cases which we have since identified, four patients were referred with a provisional clinical diagnosis of self-induction.

Gastaut and Bert wrote 25 years ago." "Yet it now seems necessary to go beyond the static 
conditions of EEG recording as performed with eyes closed, to try and study the bioelectrical cerebral modifications in conditions as close as possible to those of life itself, ie with the eyes opened in front of diverse and changing situations." These observations seem very relevant to the present case. It is suggested that self-induction of discharges or indeed of seizures is no great rarity but to establish the diagnosis one must perform prolonged EEG recordings in photosensive subjects, with opened eyes and so far as possible under natural conditions.

This paper was given at a meeting of the German, Danish, Dutch and Swiss sections of the International League against Epilepsy, Kiel, 1979. This work was supported by a grant from the Fonds voor Epilepsiebestrijding "De Macht Van Het Kleine." Our thanks are due to Dr F Lopes da Silva, who drew our attention to the possible role of the Evans-Mulholland-effect.

\section{References}

1 Andermann K, Oaks G, Berman S et al. Selfinduced epilepsy. Arch Neurol 1962; 6:49-65.

2 Bickford RG, Sem-Jacobsen CW, White PT, Daly D. Some observations on the mechanisms of photic and photo-metrazol activation. Electroenceph Clin Neurophysiol 1952; 4:275-82.

3 Darby CE, De Korte RA, Binnie CD, Wilkins AJ. The self-induction of epileptic seizures by eyeclosure. Epilepsia 1980; (in press).

4 Domyslawski M. Kość B. Padaczka fotogenna z samoprowokacja napadów. Neur Neurochir Pol 1973; 7:273-5.

5 Dooze $H$, Gerken $H$. On the genetics of EEGanomalies in childhood IV. Photoconvulsive reaction. Neuropädiat 1973; 4:162-7.

6 Gastaut H, Andermann K, et al. Self-induced epilepsy. Arch Neurol 1962; 6:49-65.

7 Gastaut H, Bert J. EEG changes during cinematographic presentation. Electroenceph Clin
Neurophysiol 1954; 6:433-44.

8 Gastaut H, Régis H, Dongier S, Roger A. Conditionnement électroencéphalographique des décharges épileptiques et notion d'épilepsie réflexo-conditionnée. Rev Neurol 1956; 94: 829-35.

9 Green JB. Self-induced seizures: clinical and electroencephalographic studies. Arch Neurol 1966; 15:579-86.

10 Jeavons PM. The use of photic stimulation in clinical electroencephalography. Proc Electrophysiol Technol Assoc 1969; 16:225-40.

11 Jeavons PM, Harding GFA. Photosensitive Epilepsy. London: Heinemann, 1975.

12 Lewis JA. Eye-closure as a motor trigger for seizures. Neurology 1972; 22:1145-50.

13 Lloyd-Smith DL, Henderson LR. Epileptic patients showing susceptibility to photic stimulation alone. Electroenceph Clin Neurophysiol 1951 ; 3:378-9.

14 Mulholland T, Evans CR. Oculomotor function and the alpha activation cycle. Nature 1966; 211: 1278-9.

15 Radovici A, Misirliou V, Gluckman M. Epilepsie réflexe provoquée par excitations optiques des rayons solaires. Rev Neurol 1932; 1:1305-8.

16 Rail LR. The treatment of self-induced photic epilepsy. Proc A ustr Assoc Neurol 1973; 9:121-3.

17 Reilly EL, Peters JF. Relationship of some varieties of electroencephalographic photosensitivity to clinical convulsive disorders. Neurology 1973; 23:1050-7.

18 Robertson EG. Photogenic epilepsy; selfprecipitated attacks. Brain 1954; 77:232-51.

19 Stefansson SB, Darby CE, Wilkins AJ, et al. Television epilepsy and pattern sensitivity. Brit Med J 1977; ii:88-90.

20 Storm van Leeuwen W, Bekkering DH. Some results obtained with the EEG-spectrograph. Electroenceph Clin Neurophysiol 1958; 10:563-70.

21 Wadlington WB, Riley HD. Light-induced seizures. J Pediat 1965; 66:300-12.

22 Wilkins AJ, Darby CE, Binnie CD, et al. Television epilepsy-the role of pattern. Electroenceph Clin Neurophysiol 1979; 47:163-71. 